\title{
Large System Multi-objective Model of Optimal Allocation for Water Resources in Jiansanjiang Branch Bureau*
}

\author{
Ping Lv and Dong Liu ${ }^{* *}$ \\ School of Water Conservancy \& Civil Engineering, Northeast Agricultural University, \\ Harbin Heilongjiang 150030, China \\ pingping.85@163.com, liu72dong@126.com
}

\begin{abstract}
According to the imbalance development and utilization of water resources, water shortages and other issues in Sanjiang Plain, taking Jiansanjiang branch bureau as an example, the multi-objective optimal allocation model of water resources is established with goal of maximum economic and social benefits. Only surface water, groundwater and transit water are considered overall and different water demands in industry, life and agriculture are satisfied can we realize the rational allocation of regional water resources. The large system decomposition-coordination theory and multiobjective genetic algorithm are applied to solve the model. The optimization results showed that, the water shortage situation in Jiansanjiang branch bureau is improved in planning years and surface water supply capacity can be increased gradually and groundwater resources can be effectively protected. The optimal allocation model and solution method are effective and feasible, and the optimal allocation results are reasonable. The research can provide scientific basis for rational development and utilization of water resources in Jiansanjiang branch bureau and Sanjiang Plain.
\end{abstract}

Keywords: Jiansanjiang branch bureau, optimal allocation of water resources, multi-objective genetic algorithm, large system decomposition-coordination.

\section{Introduction}

Optimal allocation of water resources refers to the scientific and rational allocation of limited and different forms water resources, with both engineering and nonengineering measures in a particular watershed or region. The purpose is to achieve the sustainable utilization of water resources, to coordinate the benefit conflict between each region and water use department, to improve the regional overall water consumption efficiency as much as possible[1], to ensure the harmonious development of social economy, resources and ecological environment to get the biggest integrative benefit which including economic, environmental and social benefits and other goals.

\footnotetext{
* Main research direction is agriculture and water resources system analysis and optimal using. ** Corresponding author.
} 
Jiansanjiang branch bureau locates in northeast of Heilongjiang Province and belongs to Sanjiang Plain, which is an important grain production area in China. The total area is $12300 \mathrm{~km}^{2}$ [2], with cultivated acreage of $682000 \mathrm{hm}^{2}$ [3], and the main grain crop is paddy. In recent years, the paddy is planted in mostly field as the economic benefits, then the demand of water resources for irrigation is increasing rapidly. The issues such as over-exploitation of groundwater and imbalance utilization of groundwater-surface water are serious in several areas[4]. It is necessary to optimize the water resources scientifically and reasonably, in order to utilize the limited water resources legitimately and develop sustainable agricultural and improve utilization efficiency of water resources.

As the complexity of water resources system and multi-objective optimization problem, the traditional planning methods are difficult to solve such problems. The genetic algorithm has been considered to be the most suitable method for multiobjective optimization[5], so large system decomposition coordination theory and multi-objective genetic algorithm are introduced into the solution of water resources optimal allocation model in this article.

\section{The Establishing of Multi-objective Model of Optimal Allocation}

\subsection{Description of the Decision Variables}

The regional water source which based on the water delivery range can be classifying into public and independent water sources two types. Public water source simultaneously supplies water to two or more subareas, such as mainstream transit water. Independent water source only supplies water to its own subareas, such as local interval runoff and groundwater[6].

Assuming that there are $K$ subareas and $M$ public water sources in the regional water resources system, and $C(k)$ independent water sources in $k$ subarea[7, 8]. So $k$ subarea has $I(k)=C(k)+M$ water supply sources. Define $R^{k}=\left(r_{i j}^{k}\right)_{m \times n}$, the supply and demand relationship matrix between water sources and users in $k$ subarea; $r_{i j}^{k}$,the supply-demand relation coefficient between water sources and users in the subarea, $i=1$ to $m$, different water supply sources; $j=1$ to $n$, different water use departments. $r_{i j}^{k}=1$ when there is the supply-demand relationship between the water source $i$ and the user $j$, otherwise $r_{i j}^{k}=0$.

Referring the water supply quantity $x_{i j}$ from water source $i$ to user $j$ as the decision variable, then the decision variable in $k$ subarea is described as follow:

$$
X^{k}=\left[\begin{array}{cccc}
x_{11}^{k} & x_{12}^{k} & \cdots & x_{1, J(k)}^{k} \\
x_{21}^{k} & x_{22}^{k} & \cdots & x_{2, J(k)}^{k} \\
\vdots & \vdots & \ddots & \vdots \\
x_{I(k), 1}^{k} & x_{I(k), 2}^{k} & \cdots & x_{I(k), J(k)}^{k}
\end{array}\right]
$$


Where, $I(k)$, the number of water supply sources in $k$ subarea; $J(k)$, the number of water use departments(including domestic, industrial, agricultural and other departments)in $k$ subarea.

$x_{i j}^{k}$ is corresponding to the coefficient $r_{i j}^{k} \cdot r_{i j}^{k}=0$, water source $i$ does not supply water to department $j$ in $k$ subarea, so $x_{i j}^{k}=0 ; r_{i j}^{k}=1$, water source $i$ supplies water to department $j$ in $k$ subarea, then $x_{i j}^{k} \geq 0$.

\subsection{Objective Function}

The article follows the regional sustainable development ideology, taking the regional economic and social benefits as goals to establish the optimal allocation model[9-11].

(1) Economic goal. The economic net benefits produced by different water use departments of region are maximum in the target year.

$$
\max f_{1}(x)=\max \sum_{k=1}^{K} \sum_{j=1}^{J(k)} \sum_{i=1}^{I(k)}\left(b_{i j}^{k}-c_{i j}^{k}\right) x_{i j}^{k} \alpha_{i}^{k} \beta_{j}^{k}
$$

Where, $x_{i j}^{k}$, the water supply quantity from water source $i$ to user $j$ in $k$ subarea $\left(10^{4} \mathrm{~m}^{3}\right) ; b_{i j}^{k}$, the benefit coefficient of water supply from water source $i$ to user $j$ in $k$ subarea $\left(10^{4} \mathrm{Yuan} / \mathrm{m}^{3}\right) ; c_{i j}^{k}$, the cost coefficient of water supply from water source $i$ to user $j$ in $k$ subarea $\left(10^{4} \mathrm{Yuan} / \mathrm{m}^{3}\right) ; \alpha_{i}^{k}$, the water supply order coefficient of water source $i$ in $k$ subarea; $\beta_{j}^{k}$, the water use fair coefficient of user $j$ in $k$ subarea.

(2) Social goal. The total water shortage quantity of region is minimum in the target year.

$$
\max f_{2}(x)=-\min \sum_{k=1}^{K} \sum_{j=1}^{J(k)}\left(D_{j}^{k}-\sum_{i}^{I(k)} x_{i j}^{k}\right)
$$

Where, $D_{j}^{k}$, the water demand quantity of user $j$ in $k$ subarea $\left(10^{4} \mathrm{~m}^{3}\right)$.

\subsection{Constraints}

The constraints of water resources optimal allocation model is mainly considering the water supply capacity constraints of water supply system and water demand capacity constraints of water use system of region.

(1) Water supply constraints

$$
\text { Public water source: }\left\{\begin{array}{l}
\sum_{j=1}^{J(k)} x_{m j}^{k} \leq W_{m}^{k} \\
\sum_{k=1}^{K} W_{m}^{k} \leq W_{m}
\end{array}\right.
$$




$$
\text { Independent water source: } \sum_{j=1}^{J(k)} x_{c j}^{k} \leq W_{c}^{k}
$$

Where, $x_{m j}^{k}$ and $x_{c j}^{k}$, the water supply quantity form public water source $m$ and independent water source $c$ to user $j$ in $k$ subarea $\left(10^{4} \mathrm{~m}^{3}\right) ; W_{m}^{k}$ and $W_{c}^{k}$, the water supply capacity of public water source $m$ and independent water source $c$ in $k$ subarea $\left(10^{4} \mathrm{~m}^{3}\right) ; W_{m}$, the water supply capacity of public water source $m\left(10^{4} \mathrm{~m}^{3}\right)$.

(2) Water demand constraints

$$
L_{j}^{k} \leq \sum_{i=1}^{I(k)} x_{i j}^{k} \leq H_{j}^{k}
$$

Where, $L_{j}^{k}$ and $H_{j}^{k}$, the lower and the upper limit of water demand department $j$ in $k$ subarea $\left(10^{4} \mathrm{~m}^{3}\right)$.

(3) Nonnegative variable constraints

$$
x_{i j}^{k} \geq 0
$$

\section{Mode Solution}

\subsection{The Process of Large System Decomposition-Coordination}

Large system decomposition-coordination theory can be applied to establish the large system multi-object optimal allocation model for above large-scale water resources system with multi-source and multi-user[12]. According to the theory of large system decomposition-coordination and the actual condition of water resources supply and demand, two-stage hierarchical multi-objective optimization model is established[13]. The related constraint variables also are the regional public water resources are allocated in advance which make the system divided into $K$ independent subsystems by the model coordination method. Then the distribution amount is coordinated repeatedly until the best integrated goal of system is achieved (Figure.1).

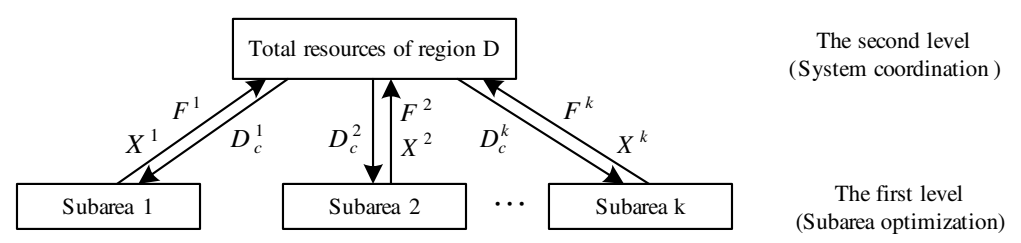

Fig. 1. The level transfer decomposition-coordination structure of water resources optimal allocation

Figure.1 shows that the model after large system decomposition-coordination is actually going to achieve two-level optimizations, which are the allocation of water sources between different users in each subarea and water quantity between subareas[14]. 
(1) The optimization of first level subsystem

The region is divided into $K$ subareas based on the natural geographical or administrative conditions in the first level. Each subarea optimize inside independently, under the premise of a given water resources amount from the second level (coordination level), which satisfied $\sum_{k=1}^{K} D_{c}^{k}=W_{c}$. The optimization of subarea is still a multi-objective optimal allocation model which solved by accelerated multiobject genetic algorithm. The internal optimal solution in each subarea and the corresponding fitness value are not necessarily the best balanced solution of region. Therefore, we need to feed back the optimal solution $X^{k}\left(D_{c}^{k}\right)$ and the target value $F^{k}\left(X^{k}, D_{c}^{k}\right)$ in each subarea that got from the first level to the second level, and do the second level system coordination.

(2) The coordination of second level system

The task of the second level coordination is to get the optimal allocation of public resources in subareas, to coordinate the partial optimal solution of each subarea to find the best balanced solution of the entire region. The solution of the second level coordination is still solved by accelerated multi-object genetic algorithm. The main steps are as follows:

(1) Producing the pre-allocated resources $D_{c}^{k}$, and transferring them to each subarea in the first level.

(2) Optimizing the first level subsystem, and getting the feedback value of the first level.

(3) Doing the genetic operation based on the feedback information, and getting the new pre-allocated project.

(4) Cycle calculation until the solution satisfied the termination requirement or the number of evolution generation, and getting the optimal allocation of water resources.

\subsection{Multi-objective Genetic Algorithm}

The genetic algorithm does not require the problem with the requirements of linearity, continuation, convexity and others, and it has high computation efficiency, global search ability and strong robustness[15,16] compared with other traditional algorithms. The population in genetic algorithm is made up of individuals, in which each individual corresponds to a basic water supply allocation program in the water resources system. The size of population is determined by the number of individuals. The greater the population or the more individuals, the more pre-allocated programs.

According to the features of water resources multi-objective optimization, the calculation method of fitness that based on the sort in the paper only depends on the multi-objective itself. Therefore, we can rank all individuals in the population separately by their responds to different objective functions, and calculate the total fitness. Thus, an individual in the genetic algorithm population is a allocation program of water resources, and each program reflects multi-objective function values[17]. 
$f(i) \quad(i=1$ to $n)$ stands for the objective function, $n$ is the number of target, $N$ is the total number of individual. For each goal $i$, every individual will generate a sorting sequence $\vec{X}_{i}$ of feasible solution based on the quality of function value. The overall performance of individuals to all objective functions can be got after sorting each goal. According to the sorting of the individual calculated the fitness:

$$
\begin{gathered}
F_{i}\left(X_{j}\right)=\left\{\begin{array}{cc}
\left(N-Y_{i}\left(X_{j}\right)\right)^{2} & Y_{i}\left(X_{j}\right)>1 ; \\
k N^{2} & Y_{i}\left(X_{j}\right)=1 ;
\end{array} \quad i=1,2, \cdots, n\right. \\
F\left(X_{j}\right)=\sum_{i=1}^{n} F_{i}\left(X_{j}\right) \quad j=1,2, \cdots, n
\end{gathered}
$$

Where, $n$, the total number of objective function; $N$, the total individual number; $X_{j}$, the individual $j$ of the population; $Y_{i}\left(X_{j}\right)$, the serial number of $X_{j}$ to the target $i$ in the population; $F_{i}\left(X_{j}\right)$, the fitness of $X_{j}$ to target $I ; F\left(X_{j}\right)$, the comprehensive fitness of $X_{j}$ to all targets; $K$, a constant between 1 and 2 , which is used to increase the fitness when the function value of individual is optimal.

The above formula shows that, the better the individual represent the greater fitness it will get, and acquire more opportunities of involving in the evolution[18]. The individual that has the optimal overall performance is the best program for the multiobjective function in all solutions.

\section{Case Study}

\subsection{Model Parameters}

Jiansanjiang branch bureau is divided into 15 subareas according to its administrative division of farms, they are Farm Bawujiu, Shengli, Qixing, Qindeli, Daxing, Qinglongshan, Qianjin, Chuangye, Hongwei, Qianshao, Qianfeng, Honghe, Yalvhe, Erdaohe and Nongjiang. Each subarea has groundwater, surface water and transit water three forms of water sources. Groundwater and surface water are independent water sources, and transit water is public water sources. In this plan, we only consider domestic, agricultural and industrial water use departments. The planning years are 2010, 2015 and 2020.

In this plan, in order to protect local limited groundwater resources, to improve ecological environment, we should gradually control the exploitation of groundwater and improve the utilization of surface water resources. Therefore conforming the groundwater exploitation extent of each farm are 50\%(moderate intensity), $40 \%$ (moderate intensity) and 30\%(moderate intensity), and the supply of surface water are $10 \%, 15 \%$ and $20 \%$ of the multi-year average surface water resources. Heilong River and Ussuri River are the main transit water resources in the region, in the future, Heilong River can supply water $11.98 \times 10^{8} \mathrm{~m}^{3}, 12.41 \times 10^{8} \mathrm{~m}^{3}$ and $12.84 \times 10^{8} \mathrm{~m}^{3}$, and Ussuri River can supply $5.15 \times 10^{8} \mathrm{~m}^{3}, 5.27 \times 10^{8} \mathrm{~m}^{3}$ and $5.39 \times 10^{8} \mathrm{~m}^{3}$. 
The industrial and domestic water demand are calculated according to the development goals of production value, industrial water use quota, the development scale of population and the per capita water use quota. The agricultural water demand is calculated based on the irrigation quota, the area of crops and the utilization coefficients of irrigation water.

\subsection{Results and Analysis}

The calculation parameters of genetic algorithm are as follows: the population size $N=200$, the crossover probability $P_{c}=0.8$, mutation probability $P_{m}=0.2$, the random number of mutation direction required $M=10$ and the acceleration times $C_{i}=10$.

Due to the length limitations, the water resources optimal allocation results of Farm Qixing in the future years are listed only in this article (Table 1).

Table 1. The water resources optimal allocation results of Farm Qixing (Unit: $10^{4} \mathrm{~m}^{3}$ )

\begin{tabular}{|c|c|c|c|c|c|c|c|}
\hline \multirow[b]{2}{*}{ Year } & \multirow{2}{*}{$\begin{array}{c}\text { Water } \\
\text { consumption } \\
\text { department }\end{array}$} & \multicolumn{3}{|c|}{ Water resources } & \multirow{2}{*}{$\begin{array}{l}\text { Water } \\
\text { supply }\end{array}$} & \multirow{2}{*}{$\begin{array}{l}\text { Water } \\
\text { demand }\end{array}$} & \multirow{2}{*}{$\begin{array}{c}\text { Water } \\
\text { shortage }\end{array}$} \\
\hline & & $\begin{array}{l}\text { Ground } \\
\text { water }\end{array}$ & $\begin{array}{l}\text { Surface } \\
\text { water }\end{array}$ & $\begin{array}{l}\text { Transit } \\
\text { water }\end{array}$ & & & \\
\hline \multirow{4}{*}{2010} & $\begin{array}{l}\text { Domestic } \\
\text { water }\end{array}$ & 191.47 & 53.92 & 1.73 & 247.13 & 247.36 & 0.23 \\
\hline & $\begin{array}{l}\text { Agricultural } \\
\text { water }\end{array}$ & 7192.10 & 699.23 & 20790.00 & 28681.33 & 29012.04 & 330.71 \\
\hline & $\begin{array}{l}\text { Industrial } \\
\text { water }\end{array}$ & 46.42 & 47.00 & 64.47 & 157.89 & 159.19 & 1.30 \\
\hline & Total & 7429.99 & 800.15 & 20856.20 & 29086.34 & 29418.60 & 332.26 \\
\hline \multirow{4}{*}{2015} & $\begin{array}{l}\text { Domestic } \\
\text { water }\end{array}$ & 239.18 & 16.36 & 16.52 & 272.07 & 272.18 & 0.11 \\
\hline & $\begin{array}{l}\text { Agricultural } \\
\text { water }\end{array}$ & 5684.50 & 1067.35 & 21363.00 & 28114.85 & 28345.23 & 230.38 \\
\hline & $\begin{array}{l}\text { Industrial } \\
\text { water }\end{array}$ & 22.87 & 121.41 & 55.06 & 199.34 & 199.72 & 0.38 \\
\hline & Total & 5946.55 & 1205.12 & 21434.59 & 28586.26 & 28817.13 & 230.87 \\
\hline \multirow{4}{*}{2020} & $\begin{array}{l}\text { Domestic } \\
\text { water }\end{array}$ & 278.47 & 24.43 & 4.91 & 307.81 & 307.82 & 0.01 \\
\hline & $\begin{array}{l}\text { Agricultural } \\
\text { water }\end{array}$ & 4055.10 & 1497.90 & 22045.00 & 27598.00 & 27667.85 & 69.85 \\
\hline & $\begin{array}{l}\text { Industrial } \\
\text { water }\end{array}$ & 124.76 & 79.81 & 33.07 & 237.64 & 237.91 & 0.27 \\
\hline & Total & 4458.33 & 1602.15 & 22082.97 & 28143.45 & 28213.57 & 70.12 \\
\hline
\end{tabular}

Table 1 shows that, along with the population growth and socio-economic development, domestic and industrial water supply both represent the trend of steady increase, agricultural water supply decreased each year in Farm Qixing. The variation trend is same as the water demand prediction. 
The water sources supply structure of each water use department shows that, domestic water is mainly supplied by groundwater, agricultural and industrial water supply are shared by groundwater, surface water and transit water. In this allocation, transit water resources gradually assume the most water demand, which remits the shortage situation of groundwater supply and protect the local groundwater resources effectively.

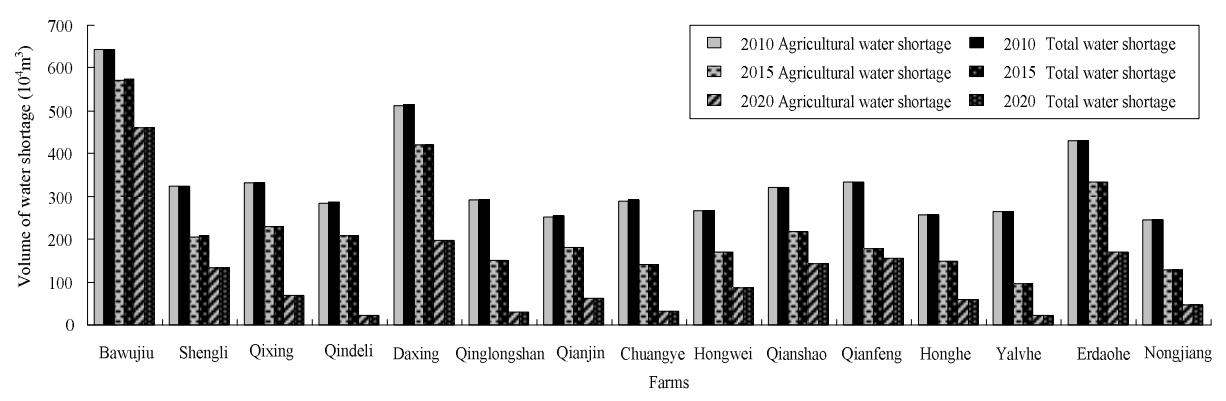

Fig. 2. The comparison between agricultural water shortage and total water shortage in Jiansanjiang branch bureau in future years

Under the condition of total water supply can not satisfied the demand, agricultural water shortage is the main representation (Figure.2). The reasons on the one hand, the paddy area is increasing massively to meet the food production demand, but the water supply cannot quickly satisfy the irrigation water requirements. On the other hand, the quantity and quality of irrigation and water conservancy facilities cannot follow the increment speed of irrigation water demand.

From the comparison results of water shortages we can see that, along with the gradually constructing of water conservancy project, the condition of water shortage improving gradually, and the volume of water shortage decreasing yearly.

\section{Conclusions}

This paper considering the multi-object character in the optimization of water resources system, established the water resources system multi-objective optimization model in Jiansanjiang branch bureau, taking the economic and social maximum benefits as the objective function, the water supply capacity, water demand capacity of water use system and variable non-negative as the constraints. The large system decomposition-coordination theory is applied and the model is solved by the real coding based accelerating genetic algorithm, the water resources optimal allocation results of each water use department in 2010, 2015 and 2020 are obtained.

The optimization results show that, the condition of water shortage improving gradually, the utilization efficiency of surface water resources is increasing and the local groundwater resources are effectively protected in planning years. Thus the optimal allocation model and solution method are effective and feasible, and the 
optimal allocation results are reasonable. The results can support scientific evidence for water resources optimization in Jiansanjiang branch bureau in the future.

On the other hand, the shortage of agriculture water is still severe. In order to solve this problem, we should control the growth rate of paddy planting, increase the utilization efficiency of irrigation water and reduce the irrigation quota.

Acknowledgments. Thanks to the support of the National Natural Science Foundation of China (No.41071053), Postdoctoral Science Foundation of China (No.20080440832), Postdoctoral Science Foundation Special Funds of China (No.201003410), Specialized Research Foundation of Colleges and Universities Doctoral Program (No.20102325120009), National Natural Science Foundation of Heilongjiang Province (No.C201026), Science and Technology Research Project of the Education Bureau in Heilongjiang Province (No.11541024) and Doctoral Start-up Foundation of Northeast Agricultural University (No.2009RC37).

\section{References}

1. Xu, X., Wang, H., Gan, H., et al.: Macro-economic water resources planning theory and method in North China. Yellow River Water Conservancy Press, Zhengzhou (1997)

2. Guo, L., Ma, K., Zhang, Y.: Landscape assessment on wetland degradation during thirty years in Jiansanjiang region of Sanjiang Plain, Northeast China. Acta Ecologica Sinica 29(6), 3126-3135 (2009)

3. Zhao, Q.: Research on the trend of underground water change in Jiansanjiang area based on gray prediction. Journal of Water Resources and Water Engineering 20(5), 128-130, 134 (2009)

4. Li, H., An, R., Wei, Y.: Applying of the $\operatorname{GM}(1,1)$ model to forecast the groundwater movement in Jiansanjiang land reclamation area. Journal of Agricultural Mechanization Research (3), 42-44 (2007)

5. Lu, X., Tan, Y.: Study on multi-objective genetic algorithm. Journal of Nanyang Teachers' College 3(9), 62-64 (2004)

6. Deng, C.: Study on model and it's application of regional water resources optimal allocation. Wuhan University, Wuhan (2005)

7. Smith, T.F., Waterman, M.S.: Identification of Common Molecular Subsequences. J. Mol. Biol. 147, 195-197 (1981)

8. Tang, D.: A model of multiobjective optimal allocation of water resources in Yellow River Basin. Journal of Hohai University (Natural Sciences) (1), 46-52 (1994)

9. Hei, B.: An optimum model of large scale system for optimum allocation of regional water resources. Journal of Wuhan University of Hydraulic and Electric Engineering (5), 110 118 (1988)

10. Hipel Keith, W.: Multiple Objective Decision Making in Water Resource. Water Resource Bulletin 28(1), 187-203 (1992)

11. Buras, N.: Operation of a Complex Water Resource Utilization System. In: Intern. Conf. Water for Peace, Washington D.C (1967)

12. Feng, S.: Multi-objective decision theory and application. Huazhong University of Science and Technology Press, Wuhan (1990)

13. Feng, S.: Water resources system engineering. Hubei Science and Technology Press, Wuhan (1991) 
14. Hei, B., Zhou, L., Ma, X., et al.: Optimal allocation model of regional water resources based on genetic algorithm. Hydroelectric Energy 20(3), 10-12 (2002)

15. Chen, N., Li, Y., Xu, C.: Optimal deployment of water resources based on multi-objective genetic algorithm. Journal of Hydraulic Engineering 37(3), 308-313 (2006)

16. Yang, K., Zhang, J., Hu, T.: Application of genetic algorithms in identification of water production parameters. China Rural Water and Hydropower (8), 10-13 (2002)

17. Liu, X., Fu, Q., Cui, H., et al.: A large system decomposition coordination model of optimal operation on water resoures in Chahayang Irrigation District. China Rural Water and Hydropower (11), 15-18 (2008)

18. Chen, N.: Theory and practice of complex system water resources reasonable disposition. Xi' an University of Technology, Xi' an (2006)

19. You, J., Ji, C., Fu, X.: New method for solving multi-objective problem based on genetic algorithm. Journal of Hydraulic Engineering (3), 64-69 (2003) 